\section{UM ESTUDO SOBRE O PAPEL DA VIOLENCIA, DAS LEIS, DO ESTADO E DAS NORMAS NA CONSTRUÇÃO DO OPERÁRIO DISCIPLINADO}

\begin{abstract}
Resumo: Trala-se de um ensaio que apresenta uma leitura do Cap XXIV do livro $O$ Capital de Karl Marx, que tem como tema a chamada "acumnlação primitiva" na formação do capitalismo. Deste texto recolhi as sugestôes de Marx a respeilo do papel da violência, da relaçáo entre a violência, as lès e o Estado na construção desse "produto artificial da história moderna", o operario assalariado. Prolongo a análise marxista sobre estas relaçōes com as propostas de Foucault sobre o papel das disciplinas e das normas.

Palavras-chave: Marx - Foucault - violência - leis - Estado - acumulação primitiva - disciplina - normas - operário.
\end{abstract}

Meu objetivo neste artigo foi o de prolongar a análise feita por Marx no Cap.XXIV do livro O Capital que trata da acumulação primitiva na formação do capitalismo e estabelecer um diálogo entre ele e Foucault em torno da questão da formação do operário com a disciplina necessária ao trabalho industrial. Trabalhei, desta forma, basicamente com o Cap.XXIV do Capital (1982) e com o trabalho de Foucault La verdad y las formas juridicas (1980).

Considero que retomar a leitura de um texto clássico marxista, tão conhecido e discutido, justifica-se plenamente nos dias atuais, por tratar-se de um trabalho que analisa brilhantemente
* Doutoranda do Programa de Pós-Graduação em Sociologia da FFLCH-USP. 
Marx e Foucault: umestudo sobre o papel da violéncia, das leis, do Estado e das normas na construção do operário disciplinado Flàvia Schilling os aspectos múltiplos que envolvem uma dificuldade central, constantemente renovada: como formar, construir, fabricar os homens necessários para garantir o funcionamento de sistemas que se renovam, se modificam, se alteram constantemente?

Para não me perder nessa navegação, centrei-me em um ínício e inventei uma pergunta. O início é dado pela história da acumulação original ou primitiva segundo Marx. Meu objetivo foi o de perceber qual é o estatuto da violência na acumulação, qual é a relação entre a violência e as leis, qual é o papel das leis e do Estado nesta obra de Marx. A pergunta que Marx teria feito em seu texto, e que pede para ser respondida, é a seguinte: como se forma esse "produto artificial da história", o operário assalariado, como foi possivel transformar o proletário vogelfrei - simultaneamente livre como um pássaro e fora da lei - no operário assalariado disciplinado? (MARX,1982: 154).

Dado que a questão do sujeito é central para Foucautt, imaginei-o tentando responder à pergunta de Marx, incluindo, ao lado da violência, das leis, do papel do Estado, a importância das disciplinas e das normas, como partes intrinsicamente constitutivas dos mecanismos de poder da sociedade criando as condições para o que Marx chamou de: "a disciplina necessária ao trabalho assalariado". (MARX,1982:130)

Para que este diálogo - arriscado - acontecesse, tomei uma série de liberdades. Em relação a Marx, segui fielmente o caminho por ele apontado no capítulo já citado do livro O Capital, sobre as relações entre a violência, as leis, a sobrepopulação relativa e a coerção das relações econômicas. Percebi em Marx, em sua brilhante análise, as relações contraditórias entre as leis, o Estado e a revolução econômica em curso, os diferentes momentos dessas relações no curso desta história da formação do capitalismo, e sua "perplexidade" frente à constituição desse produto artificial da história moderna, o operário assalariado disciplinado.

E Marx, ao lado de Foucault? As críticas de Foucault a Marx, ou melhor dito, ao marxismo transformado em ciência, com todos os efeitos de poder que isto implica, são explicitas e bem 
conhecidas. "Marx, para mim não existe, Quero dizer, esta espécie de entidade que se construiu em torno de um nome próprio, e que se refere às vezes a um certo individuo, às vezes à totalidade do que escreveu e às vezes a um imenso processo histórico que deriva dele"(FOUCAULT, 1979: 164).

Preferi trabalhar com o Foucault que cita Marx sem colocar aspas, que afirma ser impossivel fazer história atualmente sem usar uma sequiência infindável de conceitos ligados direta ou indiretamente ao pensamento de Marx, que se pergunta:

"Que diferença poderia haver entre ser historiador e ser marxista...?'(FOUCAULT, 1979: 142-143).

Foucault nos diz que foi preciso esperar o século XIX-e Marx - para saber o que era a exploração e que talvez ainda não se saiba o que é o Poder. Tentemos, no decorrer da reflexão que estamos apresentando, ver algumas articulações entre esses jogos de poder, jogos fatais de poder, grandes e pequenos jogos que se expressam na violência, nas leis, no papel do Estado, nas normas.

Tanto Marx quanto Foucault unem-se na mesma paixão do conhecimento, na crítica do presente, na percepção das luzes atravessando os espaços encobertos pelas "leis da naturais" do mercado e das disciplinas; são movidos pela visão da inteligibilidade (belicosa) do mundo em que vivemos.

Estarei estabelecendo, portanto, um diálogo que não será de concordâncias, ameno, isento de conflitos. Será o jogo polêmico de dominação e retroação foucaultiano. Da vizinhança incômoda e perigosa. Porém, seguindo a sugestão de Marx : "à entrada para a ciência...como à entrada para o inferno, tem de ser posta a exigência: aqui tem de se banir toda a desconfiança/ toda a covardia tem aqui de ser morta" ", tentaremos.
Marx e Foucault: um estudo sobre o papel da violéncia, das leis, do Estado e das normasnaconstruçāo do operário disciplinado Flávia Schilling
Karl Marx citando Dante Alighieri. A Divina Comédia, no prefácio de Para a criticada economiapolitica. In:MARX, 1982. Op, cit., v, 1, p.533. 
Marx e Foucault: um estudo sobre o papel da violència. das leis. do Estado e das normas na construção do operärio disciplinado Flávia Schilling

\section{MARX: O PRIMEIRO MOMENTO DA RELAÇÃo ENTRE A VIOLÊNCIA E AS LEIS}

"A violência é a parteira de toda a velha sociedade que está grávida de uma nova. Ela própria é uma potência econômica." (MARX,1982: 145).

Contrapondo-se às teorias que explicam a acumulação primitiva ou original como sendo fruto do direito e do trabalho, Marx coloca a ênfase na violência primitiva e nada original que a possibilita. A violência é o ponto de partida. A tônica predominante é a do roubo, da pilhagem, do assassinato. Trata-se da violência sem leis, que não cria discursos, que requer a existência de homens dispostos a tudo, homens do excesso, da loucura: os conquistadores, os invasores. Porém, este é apenas o ponto de partida.

Os limites do uso da violência e os limites para a existência legítima desse tipo de homens, neste momento da acumulação primitiva, ficam claros no decorrer da leitura de Marx. Esses limites também aparecem claramente em duas obras literárias que auxiliaram na construção deste texto: Ocoração das trevas, (CONRAD, 1984) e Maluco-la novela de los descubridores. (PONCE DE LEÓN. 1989). Nestas obras são descritos estes homens do excesso, estes conquistadores, e como eles se tornam fantasmas, pesadelos a serem enterrados na mente dos vivos.

Como vemos lendo o diário da expedição de Fernando de Magalhães e o romance nele inspirado Maluco-la novela de los descubridores, estes homens, como Fernando de Magalhães, são fundamentais para o desenvolvimento do mundo capitalista que surge, mas não pertencem a este mundo novo que se conforma, são incompativeis com ele. Quando a expedição narrada no romance se prepara para sair da Espanha, já está marcada pela invisibilidade: "era como si la flota ya se hubiera perdido en algún mar ignorado... era como si hubiésemos muerto hace ya mucho tiempo..."(PONCE DE LEÓN, 1989:13) O capitão desta expedição (e de outras) deve morrer, como D.Quixote, como os homens de seus barcos; deve 
emudecer, como seu astrólogo: a aventura não pode ser narrada na sua verdade, o futuro reservado para a expedição não deve ser previsto, a memória histórica deverá apagar os sinais da brutalidade da conquista, trabalhar para o esquecimento. "Como si fuésemos extraños. Extranjeros. Como si padeciésemos de um mal terrible del que temieran contaminarse... Estábamos sí, contaminados, y de un mal más terrible que la peste negra o que la lepra, estábamos infectados de nuestros própios sueños..," (p. 13).

Pois Magalhães sonha, segue uma obsessão que não encontrará nenhum limite, voltará para a sua nave com os braços tintos de sangue, perseguirá seu "Moby Dick" pelos sete mares, e fracassará e vencerá. Não pertence ao mundo que se inicia, deseja as honras e a vida de um mundo em extinção. Quando sua expedição retorna, também não é vista: é fantasmagórica. "Éramos tán ajenos a su mundo, tán extraños a su rutina que nos habíamos vuelto invisibles" (PONCE DE LEÓN, 1989: 320). Retornam a um mundo que já não os reconhece. São o passado que já cumpriu seu objetivo e tornou-se pesadelo na mente dos vivos. A necessidade de jogar fora a riqueza tão duramente conquistada, na entrada do porto que deveria salválos, nos mostra a chave desta história que retrata os homens e os acontecimentos da fase inicial do capitalismo: eles são ineficazes agora, não usaram métodos eficientes.

Conrad (1984: 13) descreve da seguinte forma esta mesma situação, da conquista, da invasão, da violência inicial:

"Eram conquistadores...eles agarravam o que podiam simplesmente porque as coisas estavam ali para serem agarradas. Tudo se resumia em roubo com emprego da violência, agravado por assassinato em grande escala, com os homens se entregando a isso cegamente...A conquista da terra - o que, de um modo geral, significa tomá-la daqueles que têm uma pele de cor diferente da nossa ou um nariz ligeiramente mais achatado - não é uma coisa muito agradável de se ver quando observado por um tempo demasiadamente longo...".

Eles não eram colonizadores e não entendiam (ainda) que "o que nos salva é a eficiência, o amor à eficiência" (CONRAD, 1984: 13).
Marx e Foucault: um estudo sobre o papel da violéncia, das leis, do Estado e das normas na construçấo do operärio disciplinado Flávia Schilling 
Marx e Foucault: umestudo sobre o papel da violencia. das leis. do Estado e das normasnaconstruçãodooperário disciplinado Flảvia Schilling
Marx comenta a respeito: "..o tomar acaba muito depressa em toda a parte, e quando nada mais há para tomar, tem de se começar a produzir.'(MARX,1982: 66)

Em breve estes conquistadores, estes homens possuidos pelos demônios "fortes, vigorosos, de fogo no olhar, que dirigiam e dominavam os homens" (CONRAD, 1984:24), seriam substituidos por "outro tipo de demônio, frouxo, falso, de olhar pusilânime, de uma ganância insensata e despiedada" (idem), porém integrados no novo mundo, disciplinados, respeitadores de hierarquias, sem sonhos e sim com obsessões que realizariam utilizando apenas métodos eficientes.

Portanto, tanto a conquista externa quanto a conquista interna, com tudo o que isto implica de pilhagem - violência, constitui o fundamento do movimento da acumulação original.

Para Marx, neste primeiro momento, este movimento aparece como acontecendo independentemente (e até contra) as leis. Ao comentar a trasformação ocorrida, na Inglaterra, das terras aráveis em pastagens, diz que "a legislação aterrou-se perante esse revolucionamento...ela não se encontrava ainda no cume da civilização em que "Welth of the Nation", isto é, a formação de capital e o empobrecimento brutais da massa popular, valem como última Thule de toda a sageza do Estado.'(MARX,1982: 110).

Relata as tentativas legais de colocar um freio no movimento de expropriação, leis que sistematicamente fracassam e são ignoradas.

Sobre o roubo dos domínios que pertenciam ao Estado, comenta que este realizou-se "sem a observação da etiqueta legal", e narra a mesma situação acontecendo em relação ao roubo da propriedade comunal: "o processo completou-se como violento ato individual,contra o qual a legislação há 150 anos luta em vão" (MARX,1982: 116).

Marx marca, desta forma, os limites da lei em épocas de revolucionamento. Comentando um autor que se pergunta: "O poder do capitalista sobre a riqueza do país é uma mudança completa no direito de propriedade, e por que leis-ou série de leis 
- foi ele efetuado?"... Diz Marx que o autor deveria ter-se lembrado "que as revoluções näo se fazem por leis"..."

Esse momenţo de descompasso, de leis tentando barrar o movimento de passagem para um novo sistema, exemplificaria (com Marx restringindo esse fenômeno às sociedades em que o Estado moderno ainda não foi totalmente constituído, em que as ordens sociais não se desenvolveram completamente em classes) um momento caracterizado pelo fato de que "os individuos...tenham desenvolvimentos completamente diferentes e que um interesse anterior, cuja forma de intercâmbio característica já tenha sido desalojada por uma posterior, ainda por longo tempo continue na posse de um poder tradicional na comunidade aparente (Estado, Direito) que se autonomizou face aos indivíduos..."(MARX, 1982: $64)^{3}$

Porém Marx poderia acrescentar: as revoluções não se fazem por leis, porém são por elas apoiadas, reforçadas, mesmo que nesse primeiro momento de forma contraditória, mesmo com o descompasso por ele apontado.

A acumulação primitiva ocorre, de certa forma, independentemente da tradição expressa nas leis, contra a tradição expressa nas leis. Pareceria que acontece "à revelia" do Estado. Isto não é simplesmente assim, pois neste momento devemos nos lembrar de que, simultaneamente às leis que tentam frear o processo de expropriação (no caso as expropriações internas), existem outras que o indicam e fortalecem. Vemos o sistema colonial, o sistema de dívida do Estado atuando como elementos impulsionadores do processo de acumulação original, como Marx assinala.

Caberia talvez tentar ver, neste primeiro momento que estudamos, a ineficácia das leis (ou o papel das mesmas), apontada por Marx, expressando as lutas que estão ocorrendo na sociedade que se transforma, revelando uma luta de interesses contrapostos, onde a força não está, obviamente, do lado dos "espoliados" internos e externos.
Marx e Foucault: um estudo sobre o papel da violència, das leis, do Estado e das normasna construção do operário disciplinado Flávia Schilling

Karl Marx citando Theodore Hodgskin. In: O Capital (Capitulo XXIV), Op. cit. p. 144 .

MARX, Karl. Teses para Feuerbach. Op. cit, p. 64. Nesta mesma obra, vemos a seguinte afirmação: "também a luta prática destes interesses particulares que REALMENTE se opõem constantemente aos interesses comunitários e aos interesses comunitários ilusórios, torna necessários a intervenção e o refreamento práticos pelo interesse "geral" ilusório como Estado", 
Marx e Foucault: um estudo sobre o papel da violència, das le is, do Estado e das normas naconstrução do operário disciplinado Flávia Schilling

\author{
MARX: O SEGUNDO MOMENTO DA \\ RELAÇĀO ENTRE A VIOLÊNCIA E AS LEIS
}

A partir do Século XVIII, essa situação de "descompasso" termina e Marx aponta para o papel das leis e do Estado reforçando ativamente o movimento da acumulação primitiva. Citando a leí para a vedação dos terrenos comunais, uma lei geral do Parlamento inglês, diz que "a própria lei se torna veículo do roubo da terra do povo."(MARX,1982:116).

As leis que descreve no decorrer do capitulo XXIV, que estamos analisando, podem ser classificadas em dois grupos: as le is destinadas a acelerar o processo capitalista da acumulação (formação de capital) e aquelas "contra os pobres", leis de compulsão ao trabalho, de regulação do trabalho assalariado.

Trata-se do Estado interferindo positivamente no duplo movimento essencial do capitalismo: o da transformação do dinheiro e do produto em capital e em mercadoria e o dos produtores em trabalhadores assalariados "livres", que nem pertençam diretamente aos meios de produção, nem os possuam mais.

Marx menciona, dentro do primeiro grupo de leis, aquelas que regulam o sistema colonial, o sistema da dívida pública, o sistema de impostos moderno e o protecionismo. Relatando o caso da França nos dizque "o capital original do industrial emanou aí em parte diretamente do Tesouro do Estado", pois "a dívida pública tornou-se uma das mais enérgicas alavancas da acumulação original" (MARX, 1982: 151).

E, de forma geral:

"todos eles utilizam...o Poder do Estado, o poder concentrado e organizado da sociedade para acelerar, como em estufa, o processo de transformaçăo do modo de produção feudal em capitalista e encurtar a transição."

O Estado aparece, portanto, como um fator fundamental, positivo-alavanca, suporte, estufa - para a acumulação de capital e para a regulação do outro lado imprescindivel do sistema capitalista: o trabalho assalariado. Neste segundo momento, ele é mostra- 
do por Marx, dentro de sua concepção do Estado Moderno, como respondendo fielmente aos interesses das classes dominantes, e não como um espaço com uma certa autonomização frente às "ordens sociais". Haveriam sido eliminadas as fissuras e os descompassos. De forma muito relativa, pois, no relato que Marx faz do segundo grupo de leis (as leis contra os pobres) veremos o Estado novamente colocado numa outra situação.

O segundo grupo de leis trata do trabalho assalariado:

"Surge o movimento histórico que transforma os produtores em operários assalariados".(MARX,1982: 106).

Movimento histórico fruto de uma evolução natural, racional? Não. Como no caso da acumulação original de capital, onde Marx rasga o véu colocado pelas explicações ideológicas que envolvem o processo e mostra a violência direta e a violência legal como fundamentos do mesmo, neste caso também desvenda as bases de violência direta e de violência legal que foram necessárias para criar trabalhadores livres, proletários vogelfrei. ${ }^{4}$

\section{LEIS CONTRA OS POBRES}

"Os pais da classe operária atual foram, antes do mais, castigados, pela transformação a que foram sujeitos, em vagabundos e pobres..."(MARX,1982: 126).

A lei os tratava como criminosos voluntários e "pressupunha que dependia da boa vontade deles que continuassem a trabathar nas velhas condições que já não existiam mais...."Sobre essas populações expulsas do campo foram aplicadas leis que Marx qualifica como "grotesco-terroristas"(MARX,1982: 130).

O castigo do corpo é ainda o primeiro recurso, dentro do espírito das leis e das formas de punição da Idade Média. Trata-se do corpo supliciado, marcado, que Foucault analisa extensamente em Vigiar e punir (1984) .

Essas leis "grotesco-terroristas" (assim qualificadas por Marx) visam à fixação desses homens e mulheres que vagam pelos
Marx e Foucault: um estudo sobre o papel da violência, das leis, do Estado e das normasna construção do operário disciplinado Flávia Schilling

Marx utiliza esta palavra que possui um duplo sentido muito interessante: quer dizer simultaneamente fora da lei e livre como um pássaro. 
Marx e Foucault: umestudo sobre o papel da violéncia, das leis, do Estado e das normas naconstrução dooperário disciplinado Hávia Schilling

Refere-se ao imposto dos pobres e o comentário diz respeito a uma forma de burlar estalei, que pertenceriaao primeiro momento citado por Marx, o do descompasso entre estas e a revoluçâo social e econōmica que acontece. territórios e à compulsão ao trabalho (assalariado). Além do suplício é utilizada a prisão como recurso para "arrendar os pobres da paróquia...pelo preço mais baixo pelo qual no-los tirarão das mãos.."(MARX, 1982: 113).

Marx aponta vários fatores atuando na transformação dos produtores em proletários: a violência explícita, a violência legal (prolongamento da jornada de trabalho, legislação sobre o trabalho assalariado, Estatuto dos trabalhadores, Estatuto do aprendiz, leis contra as coalizões operárias, proibição de salário superior ao mínimo estabelecido), a existência de uma sobrepopulação relativa e a compulsão surda das relações econômicas.

Qual é o papel das leis e do Estado nesta relação essencial entre trabalho e capital?

Marx ressalta que "a burguesia ascendente precisa e emprega o poder do Estado para 'regular' o trabalho assalariado"; (MARX,1982: 131) comentando a aprovação das coalizões operárias pelo Parlamento inglês "depois de ele próprio, durante cinco séculos, com desavergonhado cinismo, ter apoiado a posição de uma Trade's Union permanente dos capitalistas contra os operários.."(MARX, 1982:135), reforça a idéia de leis e Estado a serviço da classe dominante. São leis policiais-estatais que comprimem a luta de concorrência entre capital e trabalho, nos limites confortáveis do capital.

Esta situação só mudará com a "pressão das massas": as leis mudarão "ante a atitude ameaçadora do proletariado" (MARX, 1982:134). Então serão conquistados os direitos às coalizões operárias, aprovado um salário minimo legal e sancionada a duração máxima de uma jornada de trabalho. A interferência legislativa acontecerá sob pressão dos operários; Marx chama a atenção para o fato de que o resultado destas lutas "não havia de ser alcançado por acordo privado dos operários com os capitalistas....Daí a necessidade de uma ação política global, pois na ação meramente econômica, o capital é o lado mais forte.." (MARX,1982: 75).

O Estado entra, portanto, como um espaço público (o terceiro termo) para resolver situações que não se resolvem mais no 
plano do privado. Existe nesse momento, sob pressão das massas, usando a expressão de Marx, novamente uma flexibilização do papel do Estado e das leis.

Ao mesmo tempo, Marx chama a nossa atenção para um domínio onde o Estado e o poder das leis encontra um limite preciso: "O capitalista regia a fábrica por uma legislação privada sua"(MARX,1982: 134).

Qual é essa legislação privada, seu conteúdo, a justificativa que encontrou para desenvolver-se? Os trabalhadores já não estão ai, duplamente livres no mercado de trabalho?

Marx comenta que "este é um momento essencial da chamada acumulação original" (MARX, 1982:131) pois o novo sistema que se configura carece de trabalhadores, sim, mas que "tenham a disciplina necessária ao sistema de trabalho assalariado." (MARX, 1982:130)

Já não servem os antigos ritmos e formas de trabalho,já não servem apenas braços, força...Como fazer para que os "pobres ociosos" se transformem em "pobres laboriosos", como transformar esses proletários volgelfrei - fora da lei, livres como pássaros - em operários disciplinados que acreditem que "as leis do comércio são as leis da natureza e por conseguinte as leis de Deus..." ? (MARX, 1982:154) ${ }^{7}$

Transcreverei a respeito dois parágrafos de Marx:

"Não é suficiente que as condições de trabalho se coloquem, num pólo, como capital, e, no outro pólo, como homens que não têm nada que vender a não ser sua força de trabalho. Também não é sufiente forçá-los a venderem-se de livre vontade. No decurso da produção capitalista desenvolve-se uma classe operária que, por educação, tradição, hábito, admite as exigências daquele modo de produção como evidentes leis da natureza."(MARX,1982: 130).

Como acontece esse desenvolvimento, como surge essa classe operária que admite as exigências do modo de produção capitalista? Essa classe operária disciplinada? A violência, a violência das leis, a compulsão das relações ecômicas... A lei privada dos capitalistas dentro das fábricas? Jogo fácil ou jogo difícil?
Marx e Foucault: um estudo sobre o papel da violência, das leis, do Estado e das normas naconstrução do operário disciplinado Flávia Schilling

\footnotetext{
Marx comenta a respeito da expressão "pobres laboriosos" que esta "encontrase nas leis inglesas desde o momento em que a classe dos operários assalariados se torna digna de nota". (MARX, 1982: 154). Thompson retoma a expressāo em sua análise da transformação apontada por Marx e ironicamente diz do momento em que as classes ricas ociosas começam a preocupar-se com a ociosidade das classes trabalhadoras. (THOMPSON,1979:285).

Marx, comentando E. Burke. In: $O$ Capital (Capitulo XXIV). Op. cit, p. 130.
} 
Marx e Foucault: um estudo sobre o papel da violéncia. das leis, do Estado e das normas na construçãodooperário disciplinado Flávia Schilling
"Tantae molis erat [tão difícil era] destacar as "leis naturais eternas " do modo de produção capitalista, completar o processo de separação entre operários e condições de trabalho, transformar, num pólo, os meios de vida e de produção em capital, e, no pólo oposto, a massa do povo em operários assalariados, livres, esse produto artificial da história moderna." (MARX, 1982: 130)

\section{Foucallt e o Papel da violência E das leis}

Da mesma forma que Marx, Foucault também nos ensina a rir das origens solenes:

"A la solenidad de origen es necesário oponer, siguiendo un buen método histórico, la pequeñez meticulosa e inconfesable de esas fabricaciones e invenciones." (1980:22)

Imaginaremos que Foucault tentará responder a questão brilhantemente colocada por Marx sobre a constituição do operário assalariado disciplinado, esse produto artificial da história moderna, descobrindo, ao lado do contexto desenhado por Marx, outros movimentos e mecanismos do Poder. A questão marxista é, desta forma, prosseguida, olhada de perto ou de baixo. É colocada por Foucault da seguinte forma: "cómo hacer del tiempo y del cuerpo de los hombres, de su vida, fuerza productiva." (1980:136)

\section{O Contexto}

$\hat{\mathrm{E}}$, em grandes linhas, o mesmo que Marx apresenta. Um grande movimento de transformação social, revolução, explosão demográfica, novas formas de acumulação da riqueza, urbanização. A violência direta, legal ou não, é observada, mas o que Foucault procura ver, indo além, são os novos mecanismos de controle da população.

"Puede decirse que la nueva distribuición espacial y social de la riqueza industrial y agrícola hizo necesários nuevos controles sociales a finales del siglo XVIII. Los nuevos sistemas de con- 
trol social establecidos por el poder, la clase industrial y propietária, se tomaron de los controles de origen popular o semi popular y se organizaron en una versión autoritária y estatal" (1980:124).

Estes controles seriam provenientes de grupos de origem religiosa - comunidades religiosas dissidentes do anglicanismo, com a dupla função de assistência e de vigilância -, das sociedades de reforma e defesa pequeno-burguesas como a "Sociedade para a Supressão do Vício", dos grupos de autodefesa de caráter paramilitar surgidos como resposta às primeiras agitações sociais nas cidades, e do modelo das grandes companhias e sociedades comerciais.

Todos esses controles, porém, encontram seu grande modelo de inspiração nos exércitos modernos. Marx, Engels, Foucault analisam de diferentes formas a importância dos mesmos, as transformações que sugerem, sua forma peculiar de organização servindo de exemplo de manejo de grupos humanos em hospitais, fábricas, escolas e prisões. Pois, se as revoltas populares do século XVII foram revoltas camponesas, no final do século XVIII as revoltas são urbanas, e daí a necessidade de formas de poder, de gestão, capazes de controlar essas crescentes populações urbanas. Surge um novo elemento: o medo urbano. Urge separar os pobres ociosos e os pobres trabalhadores. Os pobres aparecem como perigo: perigo de doenças e perigo de revoltas. A noção de periculosidade que se desenvolve, tal como Foucault a descreve, aparece como algo totalmente contrário a todos os discursos do "Contrato", da soberania e das leis tais como estas estão colocadas, pois "la noción de periculosidad significa que el indivíduo debe ser considerado por la sociedad al nivel de sus virtualidades y no de sus actos.." (1980: 97).

Foucault sugere que é neste contexto que se inicia a "Idade da Ortopedia Social" (1980:99), do controle social panóptico, pois mais do que o confisco de bens e riquezas direto, característico do momento anterior, é preciso o desenvolvimento de mecanismos que permitam extrair trabalho dos homens.
Marx e Foucaut: um estudo sobre o papel da violència. dic leis do Estado e das normas na construçăo do operário disciplinado Flávia Schilling

Ver na obra citada de Joseph Conrad,a menção a uma "Sociedade para a supressão dos costumes bárbaros" (1984 64), que talvez fosse, mais propriamente falando, uma sociedade para a supressão dos "bárbaros", diretamente. 
Marx e Foucault: tum estudo sobre o papel da violència, das leis, do Estado e das normas na consiruçãodo operário disciplinado Flảvia Schilling
Vemos esta questao colocada ironicamente por Conrad (1984:20): "Você se esquece, meu caro Charlie, de que è o trabalhador que dignifica o seu trabalho.,"

"Blando" deve ser entendido no sentido de insidioso, envolvente, que consegue penetrar nos minimos espaços.

\section{AS LEIS CONTRA OS POBRES}

Segundo Foucault é preciso realizar a "decomposição utilitária da pobreza numa série de distinções funcionais: bons e maus pobres, ociosos voluntários e desempregados involuntários"(FOUCAULT, 1979:189), destacar as leis naturais do capitalismo até conseguir criar o trabalhador que possua a virtude do trabalho moderno: "trabalhar sem objetivo, trabalhar por trabalhar, deveria daraos individuos a forma ideal do trabalhador". (FOUCAULT. 1979:133) ${ }^{9}$ Trabalhadores que acreditem que as leis do mercado são as leis da natureza e, por conseguinte, as leis de Deus.

"Já que a sociedade industrial exige que a riqueza esteja diretamente nas mãos não daqueles que a possuem, mas daqueles que permitem a extração do lucro fazendo-a trabalhar, como proteger essa riqueza? Evidentemente, por uma moral rigorosa: dai esta formidável ofensiva de moralização sobre a população do século XIX. Foi absolutamente necessário constituir o povo como um sujeito moral..." (FOUCAULT, 1979:133)

Poderiamos continuar, usando agora as palavras de Marx, e dizer que foi absolutamente necessário constituir o povo como um sujeito moral, desenvolvendo uma classe operária que, por educação, tradição, hábito, admitisse as exigências daquele modo de produção como evidentes leis da natureza.

Estas novas formas de poder institucionais, estatais, paraestatais ou infra-estatais, conformam o que Foucault chama de um poder novo "más blando y rico" (1980:129) ${ }^{10}$, um poder que conjuga um direito de soberania e um mecanismo de disciplina, organizando técnicas laterais para assegurar, no mundo industrial, as funções de internação, reclusão e fixação da classe operária.

"Trata-se de um triângulo: soberania, disciplina, gestão governamental, que tem na população seu alvo principal e nos dispositivos de segurança seus mecanismos essenciais"'(1979:291), pois a questão colocada é a da fixação desse operariado ao corpo do aparato de produção. Pois,como Marx já nos disse, o tomar acaba muito depressa e, depois, é preciso começar a produzir... 
Desenvolvendo a análise dessas técnicas laterais ou marginais é que Foucault joga luz sobre a afirmação de Marx de que o capitalista regia a fábrica por uma legislação privada:

"La fábrica, la escuela, la prisión o los hospitales tienen por objetivo ligar al individuo al proceso de producción, formación o corrección de los productores que habrá de garantizar la producción y sus ejecutores en función de una determinada norma"(FOUCAULT, 1980: 128).

Através da disciplina (a anatomia politica do detalhe, a arte de talhar pedras), visa-se a ortopedia social, a transformação do tempo em tempo de trabalho, da força, em força de trabalho. Isto leva a que coexista, ao lado da ordem político-jurídica existente, uma ordem disciplinar ou, ao lado da lei, a norma.

"Na essência de todos os sistemas disciplinares, funciona um pequeno mecanismo penal...as disciplinas estabelecem um sistema de "infrapenalidade"; quadriculam o espaço deixado vazio pelas leis; qualificam e reprimem um conjunto de comportamentos que escapava aos grandes sistemas de castigo por sua relativa indiferença" (FOUCAULT, 1984: 159).

São as leis privadas que regem as fábricas. Pois, continuando com as palavras de Marx, não é suficiente que as condições de trabalho se coloquem, num pólo, como capital e, no outro, como homens que não têm nada a vender a não ser a sua força de trabaIho:

"Dos son las cosas necesárias para la formación de una sociedad industrial: por una parte es preciso que el tiempo de los hombres sea llevado al mercado y ofrecido a los compradores...y por otra parte es preciso que se transforme en tiempo de trabajo..." (FOUCAULT, 1980:130).

Além do tempo, o corpo precisa ser adestrado, conformado às exigências do novo sistema. Tratar-se-á de um corpo que "debe adquirir aptitudes, recibir ciertas cualidades, calificarse como cuerpo capaz de trabajar..."(FOUCAULT, 1980: 133).

Estaríamos frente a uma proposta de disciplina geral da existência que superaria os limites de cada instituição em particular,
Marx e Foucault: um estudo sobre o papel da violència, das leis, do Estado e das normas na construção do operário disciplinado Flávia Schilling 
Marx e Foucault: um estudo sobre o papel da violència, das leis, do Estado e das normas na construção do operàrio disciplinado Flávia Schilling ou seja, o limite de que a fábrica é feita para produzir, a escola para ensinar, etc. A questão é como fazer do tempo e do corpo dos homens, de sua vida, força produtiva.

Como fizemos com Marx, encerraremos este ponto do diálogo com uma citação de Foucault:

"Para que los hombres sean efectivamente colocados en el trabajo y ligados a él es necesária una operación o una série de operaciones complejas por la que los hombres se encuentran realmente, no de una manera analítica sino sintética, vinculados al aparato de producción para el que trabajan. Para que la esencia del hombre pueda representarse como trabajo se necesita la operación o la síntesis operada por un poder político... el sistema capitalista penetra mucho más profundamente en nuestra existencia... ese regimen se vio obligado a elaborar un conjunto de técnicas políticas, técnicas de poder, por las que el hombre se encuentra ligado al trabajo... pero para que haya plus-ganancia es preciso que haya subpoder, es preciso que al nivel de la existencia del hombre se haya establecido una trama de poder político microscópico, capilar, capaz de fijar a los hombres al aparato de producción, haciendo de ellos agentes productivos, trabajadores. La ligazón del hombre con el trabajo es sintética, política; es una ligazón operada por el poder"(1980:139).

Não existe mais valia sem subpoder.

Encerrando a nossa discussão, propomos as seguinte reflexões: forçamos um encontro, vimos um diálogo não ameno entre dois autores que, pertencendo a épocas e possibilidades de pensar diferentes, desenvolvem críticas radicais da atualidade. Vimos que a recuperação do texto de Marx sobre a chamada acumulação primitiva ou original do capitalismo revelou-se extremamente pertinente para a compreensão dos dias de hoje, quando vivemos novamente a discussão sobre quais e como são os homens necessários para o tipo de sociedade que se delineia sob o nome de "sociedade pós-industrial", qual é o papel da violência, das leis e do Estado, qual é o papel que jogam as surdas compulsões econômicas na construção dos novos modelos das relações de trabalho, modifi- 
cando e "aterrorizando" a legislação vigente. Vimos que a fabricação destes homens "necessários", destes trabalhadores disciplinados, que admitam as exigências do modo de produção como evidentes leis da natureza, não é fácil, acontece dentro de um contexto que é mais de guerra do que de jogo, dentro de um contexto irredutivel a uma determinação principal. Jogo ou guerra complexo, com batalhas decisivas e ganhos e perdas sempre provisórios.

SCHILLING, Flávia. Marx and Foucault-a study of violence, norms, the law, the State in the making of the disciplined worker. Plural; Sociologia, USP, S. Paulo, 4: 42-59, 1.sem. 1997.

Abstract: Starting from a new reading of Marx's Capital, chapter XXIV, the article examines the relationship between violence, the law and the State in the rise of the waged worker as a "artificial product of modern history". Foucault's ideas on the role of discipline and norms is suggested as a complement to the Marxist approach.

Uniterms: Marx - Foucault - violence - law - State - primitive accumulation discipline - norms - waged worker.

\section{Bibliografia}

ADORNO, Sérgio. Sujeito, história e poder. Estudos de Sociologia. São Paulo: USP/Depto. de Sociologia, 1991.

BASBAUM, Leoncio. No estranho pais dos iugoslavos. São Paulo: Ed. Edaglit, 1962.

CONRAD, Joseph. O coração das trevas. Belo Horizonte: Ed. Itatiaia Ltda/, 1984.

FOUCAULT, Michel. Microfisica do poder. Rio de Janeiro: Ed.Graal, 1979 ,

—. Laverdady las formas juridicas. Barcelona: Colección Hombre y Sociedad. Ed. Gedisa, 1980.
Marx e Foucault: um estudo sobre o papel da violência, das leis, do Estado e das normas na consiruçãodooperário disciplinado Flávia Schillıng 
Marx e Foucault: umestudo sobre o papel da violéncia das leis, do Estado e das normasnaconstrução dooperário disciplinado Flávia Schilling
Vigiar e punir. Petrópolis: Ed. Vozes, 1984.

KENNEDY, Paul. Ascenção e queda das grandes poténcias, Rio de Janeito: Ed. Campus, 1989.

MARX, Karl. Obras escolhidas - Marx-Engels. Lisboa-Moscou: Ed.Avante, Ed.Progresso, 1982. $2 \mathrm{v}$,

—. A Chamada Acumulação Original. Cap. XXIV do livro O Capital. Vol II.

- Teses sobre Feuerbach. Vol.1.

—. A Guerra Civil em França. Vol.II.

—. Salário, Preço e Lucro. Vol.Il.

_. O 18 de Brumário de Louis Bonaparte. Vol.1.

As Lutas de Classes em França de 1848 a 1850. Vol.1.

Trabalho Assalariado e Capital. Vol.1.

Para a Crítica da Economia Política. Vol.1.

PONCE DE LEÓN, Napoleón Baccino. Maluco - la novela de los descubridores. Havana: Ed.Casa de las Américas, 1989.

THOMPSON, E.P. Tradicion, revuelta y conciencia de clase. Barcelona: Ed Critica, 1979. 